\title{
First aid for psychoses
}

$\mathrm{F}$ rom applying band-aids and fashioning splints to phoning 911, many Canadians know the basics of physical first aid, but few know what to do or who to call in the case of a mental health emergency.

Every year, hundreds of thousands of Canadians take physical first aid training to gain the skills and confidence to prevent and mitigate injuries in emergency situations. Now, the Mental Health Commission of Canada (MHCC) is offering similar courses across the country in "mental health first aid" to help train people to provide initial support to friends and relatives who may be developing a mental health problem or are experiencing a mental health crisis (www.mental healthfirstaid.ca).

Mental health first aid was pioneered in Australia in 2001, and brought to Canada in 2006 by the Alberta Mental Health Board. The MHCC adopted the initiative on a national scale last year. To date, some 43649 mental health first aiders and 513 instructors have be trained in Canada, and the initiative is gearing up for the start of special services for high risk groups such as northern, First Nations and Inuit people.

The aim is to teach Canadians to recognize the signs and symptoms of mental disorder before a crisis situation occurs, explains Denise Waligora, manager of program education for Mental Health First Aid Canada. "It's not about diagnosing someone but about being aware of the people around you and having the confidence to approach them, provide that initial help and guide them to the appropriate professional or community resources."

Borrowing from traditional first aid courses, the program instructs participants to:

- Preserve life where a person may be in danger to themselves or others

- Provide help to prevent a mental health problem from worsening

- Promote the recovery of good mental health, and

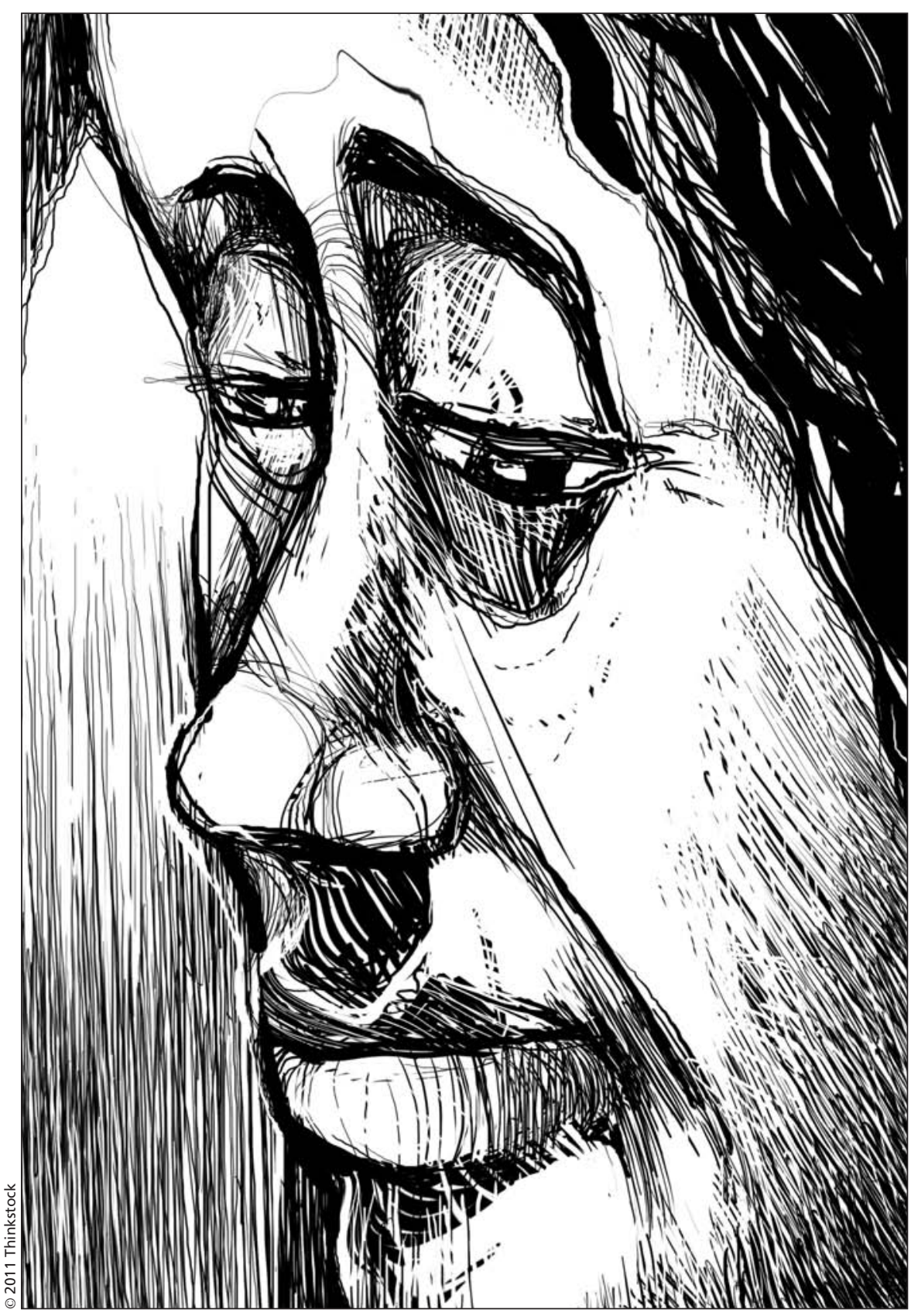

Teaching Canadians to recognize the signs and symptoms of mental disorder before a crisis situation occurs is the primary objective of mental health first aid instruction.

- Provide comfort to people experiencing mental health problems.

The course also trains participants to respond to specific crises, including cases of overdose, suicidal behaviour, panic attacks and psychosis.

Most Canadians are flummoxed, if not frightened, when they encounter someone in such serious mental distress, Waligora explains.

First aider and mother of four Kathryn Wyatt Cottingham describes her family being "blown apart" by the suicide of one of her son's friends. "We 
talk about our likelihood for things like hypertension but not things like depression. We have all these kids around us but we don't know what to do in these situations," she says. "As responsible parents we take CPR [cardiopulmonary resuscitation] courses, and I see this as being the same."

Typically, people are not only unsure of how to respond but "often think that if they offer support they'll be expected to solve all of the person's problems," Waligora says.

The program, however, emphasizes listening and explicitly warns against amateur attempts at counselling, she says. "I give the example of coming home after a rough day to vent to your partner, and they start telling you what you should do when you haven't asked for their advice."

Some people avoid offering help to a person because they fear upsetting them or believe that it won't make a difference, Waligora adds. "One of the big differences between mental health first aid and physical first aid is the timeline. You can approach someone with your concerns and they won't want to talk to you at that time, but maybe they'll come to you weeks or months later, whereas if you saw someone break their leg you could put a splint on it or call an ambulance and be done your part all at that time."

Others feel it's not their place to intervene, she says. "But depending how long a person has gone without support it can be really hard for them to reach out, and professional help might not always be on hand. Who's going to notice the change in your behaviour first, the person you see everyday or the family doctor you see every six months?"

Even those who already have access to professional help may need support navigating the system, explains first aider Dena Thomas, who took the course after her son started experiencing mental health difficulties. "We had assessments done at the university but the results never came through to our local psychiatrist, and trying to get the records was not an easy process. Everyone seemed to be working independently of each other, with no cohesion and no follow through. I can't imagine what it would be like for someone who doesn't have the support of their family."

Thomas says the course helped her "open the lines of communication" about mental health issues, not just with her son but also with friends and family. "Once you start sharing it's amazing how many people are in the same boat."

Some 170000 Australians, or $1 \%$ of the country's adult population, have attended the course since its inception (Aust N Z J Psychiatry 2011; 45[8]: Epub ahead of print). Evaluations of the Australian initiative show statistically significant benefits to participants up to six months after the training, including greater confidence about helping others and advising them to seek professional help; decreased stigma toward people with mental health problems; and improvements to the mental health of the participants themselves. The impact of the initiative on recipients of mental health first aid has yet to be evaluated.

Eighteen other countries, including the United States, China, England, Scotland, Wales, Ireland, Sweden, Japan, South Africa and New Zealand, have since launched homegrown versions of the initiative. Evaluations in Canada are ongoing. — Lauren Vogel, CMAJ

CMAJ 2011. DOI:10.1503/cmaj.109-4002 